\title{
A noção de relação com o saber: convergências e debates teóricos*
}

Jean-Yves Rochex

Université Paris-VIII

\section{Resumo}

Nos últimos 20 anos, a noção de relação com o saber difundiuse e foi usada amplamente, tanto na esfera da pesquisa em educação quanto nas da formação de docentes e de profissionais do sistema educacional ou do debate social relativo à escola. 0 êxito teórico e institucional, e até mesmo mediático, do sintagma relação com o saber indica, creio eu, convergências reais que, no entanto, não devem minimizar as questões e os debates teóricos e sociais por ele suscitados. Refletindo sobre os debates suscitados pelo uso, em perspectivas e quadros teóricos distintos, por diferentes pesquisadores e coletivos de pesquisa, de noções semelhantes (de relação com o saber, mas também de experiência escolar, por exemplo), o objetivo deste artigo é tentar esclarecer os desafios teóricos, empíricos e sociais desses debates e neles haurir novos recursos para pensar e agir.

\section{Palavras-chave}

Relação com o saber - Fracasso e desigualdades escolares - Sociologia da educação - Teoria do sujeito - Teoria da atividade. 


\title{
The notion of relation to knowledge: convergences and theoretical debates*
}

Jean-Yves Rochex

Université Paris-VIII

\begin{abstract}
During the last 20 years, the notion of relation to knowledge has become disseminated, and it has been widely employed in the fields of education research, education of teachers and other professionals in the education system, and in the social debate about school. This theoretical and institutional - and even mediatic - success of the relation to knowledge syntagm signals, in my view, to real convergences that, however, should not diminish the importance of the theoretical or social questions and debates this notion elicits. Reflecting on the debates raised by the use by various researchers and research groups of similar notions (of relation to knowledge, but also of school experience, for instance) under different perspectives and theoretical frameworks, the objective of this paper is to clarify the theoretical, empirical and social challenges entailed by these debates, and extract from them new resources to think and act.
\end{abstract}

\section{Keywords}

Relation to knowledge - School experience - School failure and inequalities - Sociology of education - Theory of the subject Activity theory.

\author{
Contact: \\ Jean-Yves ROCHEX \\ 33, rue de la Ville Neuve \\ 93600 - Aulnay-sous-Bois - France \\ e-mail: rochexjy@wanadoo.fr
}

"Published by Elsevier SAS for the French Society of Psychology. 2004. Portuguese translation by Lólio Lourenço de Oliveira. 
Nos últimos 20 anos, a noção de relação com o saber difundiu-se e foi usada amplamente, tanto na esfera da pesquisa em educação quanto nas da formação de docentes e de profissionais do sistema educacional ou do debate social relativo à escola. Objeto de uma dezena de obras, algumas das quais tiveram um êxito assaz inesperado em sua divulgação, ela se impôs, não sem alguns efeitos perversos de que trataremos mais tarde, como sintagma de grande poder de evocação para todos os que refletem sobre as questões de escola e de educação. Nada menos que novo paradigma para alguns (Chabchoub, 2000); para outros, a noção de relação com o saber antes se apresenta como uma noção cujos "contornos parecem [...] bem mal delimitados ainda que seu poder heurístico seja pouco contestável, tanto pelo que ela critica, quanto pelas possibilidades que abre" (Laterrasse et al., 2002), apreciação esta última de que me inclinaria a compartilhar, assim como compartilho da prudência de Beillerot (1996) que propõe trabalhar com essa noção, mantendo-lhe o valor de conceito problema e não fortalecê-la como conceito solução, conceito explicativo suscetível de dar lugar a toda sorte de vulgatas e extensões mais ou menos controladas. 0 êxito teórico e institucional e até mesmo mediático do sintagma, relação com o saber, indica, creio eu, convergências reais que, no entanto, não devem minimizar as questões e os debates teóricos e sociais por ele suscitados. Destes, pretendo tratar mais adiante neste artigo, a partir de um exame retrospectivo sobre as problemáticas e os trabalhos da equipe Escol da Universidade de Paris-VIIl, fundada em 1987 por Bernard Charlot, e que tem sido - com o Cref da Universidade de Paris-X, em torno de Jacky Beillerot, e o Irem de Aix-Marseille, em torno de Yves Chevallard - um dos coletivos de pesquisa em que essa noção, utilizada desde a década de 1960 nas esferas da psicanálise e da sociologia, tornou-se, nas décadas de 19801990, organizadora de uma problemática e de perspectivas de pesquisas empíricas. Refletindo sobre a história de nossa equipe e, portanto, sobre seus debates internos e, mais amplamente, sobre os suscitados pelo uso, em perspectivas e quadros teóricos distintos, e por diferentes pesquisadores e coletivos de pesquisa, de noções semelhantes (de relação com o saber, mas também de experiência escolar, por exemplo), meu objetivo é tentar esclarecer os desafios teóricos, empíricos e sociais desses debates e de neles haurir novos recursos para pensar e agir.

\section{Breve reflexão sobre os trabalhos e os debates da Escol}

Quando a equipe Escol se constituiu e realizou a pesquisa de que resultaria a publicação da obra École et savoir dans les banlieues... et ailleurs [Escola e saber na periferia... e alhures] (Charlot; Bautier; Rochex, 1992), ela retomou a noção de relação com o saber das análises teóricas anteriores de Bernard Charlot, com as quais procurou combinar abordagens provindas das ciências da linguagem e da psicanálise, para melhor pensar e estudar a questão da produção/reprodução das desigualdades sociais na escola. Tratava-se, para nós, de tentar ir mais além das explicações, profanas ou eruditas, dessa produção feitas com a ajuda de visões unilateralmente e globalmente deficitárias (explicações em termos de handicap sociocultural) ou de conceitos muito gerais e hegemônicos, tais como o conceito de código em Bernstein (e sobretudo em alguns de seus epígonos norte-americanos) ou o conceito de habitus em Bourdieu, visões e conceitos estes que mal consideram a diversidade interna dos diversos grupos sociais e pouco espaço deixam para a especificidade, a produtividade e a historicidade das atividades e instituições sociais e das biografias dos agentes ou sujeitos sociais. Gibson (1984) censurará assim Bernstein por "um uso cada vez mais hegemônico e exclusivo desse conceito [...]: o código deixa de ser um conceito com cuja ajuda procuramos compreender certas coerências, 
certas regularidades nas práticas, para tornar-se uma espécie de realidade onipotente, uma força organizadora ou instigadora, um princípio ativo, uma causa primeira e como que uma 'enteléquia' no sentido leibniziano" (Forquin, 1987). Não se pode pensar que essas observações valeriam igualmente, e nos mesmos termos, com referência ao conceito de habitus e ao postulado da homogeneidade de esquemas, disposições e práticas de um mesmo agente que lhe serve de base, postulado amplamente discutido desde então, entre outros, por Lahire (1998). Esperemos que isso não venha a ser o caso - guardadas as devidas proporções - da noção de relação com o saber.

Uma experiência profissional anterior como conselheiro de orientação fizera com que, muito cedo, me confrontasse com a importância de processos e determinantes sociais na produção de desempenhos e percursos escolares e com a impossibilidade de destruir o caráter singular de cada história escolar, esta, por sua vez, entrelaçada numa história familiar que a ultrapassa nas regularidades estatísticas e nos determinismos sociológicos e, portanto, com a necessidade, para melhor compreender e melhor agir, de uma convocação mútua e uma comprovação recíproca das teorias e conceptualizações próprias das disciplinas do social e de suas correspondentes próprias das disciplinas do psiquismo. Donde nosso cuidado em trabalhar não só sobre percursos e modos de experiências escolares e de relação com o saber e com a escola que permitam compreender processos 'comuns' de seleção e de fracasso dos alunos provindos de ambientes populares, mas também sobre casos de êxitos escolares excepcionais, atípicos relativamente às correlações estatísticas.

Certamente, nosso objetivo não era, como nos atribuíram certos comentaristas apressados, desmentir ou denegar as 'teorias da reprodução' ou os trabalhos de Bourdieu, mas sim voltar os olhos para territórios em que estes sequer se haviam aventurado e, com isso, procurar pensar a partir desses trabalhos. Tínhamos então (e mantemos sempre) a hipótese de que o estudo e a análise dos processos que permitiram a existência desses casos, certamente minoritários, mas tão mais interessantes de decifrar, de êxito escolar atípico - que observamos nos collèges ZEP e nos bairros 'desfavorecidos' em que trabalhávamos -, podiam revelar-se ricos de ensinamento, por um lado, para compreender melhor os processos de fracasso 'comum' e, por outro, para trabalhar, como outros também faziam (Lahire, 1996; Laurens, 1992; Terrail, 1990; Zéroulou, 1985), os espaços impensados dos trabalhos de sociologia crítica com os quais nos havíamos formado para a pesquisa em Educação.

Desse modo, tentamos mobilizar os trabalhos clínicos e as elaborações teóricas da psicanálise, particularmente as relativas à questão das identificações e à dos projetos familiares, para começar a tentar compreender melhor os processos de gênese das relações com o saber e dos modos de experiências escolares das crianças provindas de ambiente popular (sobre isso, cf. particularmente Rochex, 1995; Charlot; Rochex, 1996), poderiamos, assim, ir além das noções muito gerais de interiorização, de incorporação e até de condicionamento, com as quais Bourdieu se livrava algo apressadamente da questão da gênese do habitus que, nele, é bem mais explicativo do que explicado (Barthez, 1980; Héran, 1987), o que torna bastante desequilibrada a dialética 'da interiorização da exterioridade e da exteriorização da interioridade' que ele se empenha em empregar.

De modo mais geral, em Bourdieu como em grande número de sociólogos, nem o corpo nem o psiquismo possuem qualquer realidade ou leis próprias. Concebidos como mero substrato da modelagem das disposições, não podem pois nada comportar ou produzir que não seja devido à sua exterioridade. Concepção 'amorfa' do psiquismo e de seu funcionamento que absolutamente não resiste ao estudo e à análise das modalidades concretas dos processos de escolarização e de aprendizagem e da diversidade das relações com o saber, com a linguagem e com a escola, que nele se encarnam e se transformam. 
Inversamente, nosso cuidado em melhor compreender, por meio de estudos de caso, os processos de construção do 'fracasso' ou do 'êxito' escolar' em ambientes populares permitiu-nos, segundo penso, apresentar melhor algumas das provas - objetivas e subjetivas, com que se defrontam os sujeitos sociais que são os alunos - e das modalidades diferenciadas e fontes de profundas desigualdades sociais e individuais, segundo as quais eles as interpretam e as enfrentam. Não nos permitiu, porém, trabalhar suficientemente sobre os modos de relação com o saber, com a escola e com a aprendizagem dos diferentes ambientes sociais, particularmente das classes populares, a exemplo do que puderam fazer Élisabeth Bautier (1989; 1995) e Bernard Lahire (1993a; b) relativamente às práticas de linguagem e à cultura escrita. Além disso, os empréstimos que fizemos da psicanálise permitiram-nos trabalhar mais sobre a relação com a escola, que enlaça experiência escolar e projetos familiares, do que sobre a relação com o saber propriamente dita, enquanto que o recurso a materiais empíricos baseados essencialmente no declarativo (provas de conhecimento e entrevistas) não nos permitia suficientemente (salvo na análise do trabalho de linguagem efetuado pelos alunos com os quais investigávamos) confrontar esse declaratório a práticas efetivas de conhecimento.

Finalmente, estudar e analisar tipos de relação com o saber e com a escola socialmente construídos não nos permitia o acesso, a não ser muito indiretamente por meio das reconstruções dos principais interessados, à gênese delas em práticas educativas e modos de socialização familiar socialmente situados. Nesse sentido, nossos trabalhos eram e continuam a ser, no essencial, suscetíveis à mesma crítica que a acima formulada a propósito dos trabalhos de Bourdieu e da utilização que ele fez do conceito de habitus.

Assim, a obra École et savoir dans les banlieus... et ailleurs, que procurava relatar as primeiras pesquisas da equipe Escol, era, a meu ver, tanto exploratória quanto conclusiva, con- vidando a trilhar rotas de pesquisa que ela inegavelmente abria. Nem sempre, porém, foi essa a recepção que ela obteve. Sua ampla difusão para bem além dos meios da pesquisa em Educação, mas também sem dúvida certas facilidades de escrita e as insuficiências de elaboração e de explicação de que ela padecia, ligadas ao caráter exploratório dos trabalhos que ela visava relatar, acabaram dando espaço a leituras e interpretações que traduziam os processos que havíamos tentado aclarar como versão modernizada das concepções e ideologias deficitárias das quais, ao contrário, visávamos criticar o caráter unilateral e generalizador. Outros, aliás menos numerosos, acreditavam poder nela basear ou confirmar uma crítica, a meu ver, unilateralmente subjetivista e relativista da instituição escolar, que reduzia essa última ao arbitrário de sua cultura e ao desprezo, talvez até mesmo à redução dos indivíduos e das personalidades. Certamente, todo trabalho publicado escapa a seus autores e o nosso não tinha qualquer razão para escapar à regra; não obstante, essas leituras e interpretações repercutiram, de certo modo, nos debates e nas discussões internas da equipe, provisoriamente suspensas pelas pressões e necessidades da escrita coletiva, mas que, a seguir, iriam dar lugar a orientações de pesquisa sensivelmente diversas, alimentando por sua vez essas discussões e esses debates críticos, sem os quais qualquer coletivo de pesquisa fica condenado a repetir-se e a estiolar.

Foi assim que Élisabeth Bautier e eu, numa pesquisa posterior (Bautier; Rochex,1998), trabalhamos para compreender melhor as relações com o saber e os modos de experiência escolar dos nouveaux lycéens [novos estudantes de lycée] e os processos complexos e heterogêneos que participam da construção do fracasso ou do êxito no lycée. Com isso, tentamos esclarecer as relações pelo menos problemáticas entre

1. Essas categorias são certamente excessivamente dicotômicas e exigiriam ser muito mais questionadas e especificadas do que é possível fazer no âmbito deste artigo. 
massificação do acesso ao lycée e democratização do acesso aos saberes e aos modos de trabalho intelectual que, em princípio, são ali exigidos. Fizemos isso, por um lado, recorrendo a metodologias e dados de natureza diversa - e não exclusivamente declarativas, aliando, à coleta de entrevistas e de provas de conhecimento, observações em classe - e um trabalho de análise de diversos trabalhos de alunos e, por outro, dando grande importância ao trabalho de escrita, como recurso para aprender e pensar, e às negociações consigo mesmo que ele ao mesmo tempo exige e torna possíveis. Por seu lado, Bernard Charlot empenhava-se numa nova pesquisa que, em suas próprias palavras, visava menos estudar as condições de escolarização nos lycées profissionais da periferia nos quais pesquisou, do que 'a relação com o saber dos jovens de origem popular confrontados com o que se chama fracasso escolar', e isso a partir de materiais exclusivamente declaratórios (entrevistas e provas de conhecimento). Essa relação com o saber era definida de maneira extremamente ampla como

\section{[...] o conjunto (organizado) de relações que um} sujeito humano (portanto singular e social) mantém com tudo que provém do 'aprender' e do saber: objeto, 'conteúdo de pensamento', atividade, relação interpessoal, lugar, pessoa, situação, ocasião, obrigação etc., de algum modo ligados ao aprender e ao saber. (Charlot, 1999)

Uma definição como essa, retirada de uma pequena obra teórica publicada dois anos antes, atesta que o que interessa a Bernard Charlot é menos o estudo das condições concretas de escolarização, nas quais se combinam os processos de produção/reprodução das desigualdades sociais de acesso ao saber e ao êxito escolar, do que uma reflexão bem mais ampla, de orientação antropológica, sobre aquilo que ele chama de as formas ou as figuras do aprender e os processos que permitem 'compreender o mundo', cuja diversidade, segundo ele, a escola e os pesquisadores que por ela se interessam muito ganhariam em reconhecer, mais do que o fazem: "Interessam-nos aqui os processos pelos quais os indivíduos social e escolarmente subordinados põem o mundo em ordem e não aqueles pelos quais se constrói uma história escolar singular" (Charlot, 1997), assim escreve ele na obra em que relata a pesquisa realizada em lycées profissionais.

Daí a crítica dirigida, para além das convergências reais entre as duas pesquisas, ao trabalho que Elisabeth Bautier e eu havíamos dedicado a 'expérience scolaire des nouveaux lycéen': nele teríamos feito uma hierarquização implícita das diversas formas do aprender e da subjetividade e, relacionando a relação com o saber dos jovens de ambientes populares aos requisitos das aprendizagens e do trabalho de escrita específicos do lycée, não teríamos tomado suficiente cuidado para não nos deixarmos encerrar em 'uma leitura em negativo da realidade social'. Advertência revigorante e que exige um exame sério, mas que me parece basearse, ao mesmo tempo, sobre uma diferença, até mesmo um mal-entendido, quanto às duas orientações de pesquisa, e sobre uma parte de desacordo real, que merece ser explicitado, por dizer respeito a desafios a meu ver essenciais, para além dos trabalhos em questão. Por um lado, trabalhar, como Bautier e eu tentamos fazer, sobre as condições de uma escolarização bem-sucedida não se pode fazer sem levar em consideração as exigências normativas próprias da escola; por outro lado, se é evidentemente necessário questionar os modos de funcionamento da instituição escolar e a parte que lhe cabe na produção das desigualdades sociais, desde a construção de seus currículos até as práticas comuns de seus agentes, não nos parece que, por isso, essas exigências devam reduzir-se inteiramente apenas ao registro do arbitrário e do elitismo e sejam dissolvidas no ácido de uma visão relativista radical, que corre o risco de negar toda necessidade e toda normatividade própria dos saberes e das técnicas intelectuais constitutivas da cultura escolar ${ }^{2}$. De nossa parte, tememos que a legítima preocupação de

2. Cf., a este respeito, Forquin, 1989. 
Bernard Charlot de estudar e reabilitar as diversas formas e modalidades 'não escolares' do 'aprender' e da subjetividade dos jovens de ambientes populares o levem, por um lado, a subestimar o fato de que a heterogeneidade dessas formas e modalidades é origem de profundas desigualdades sociais, diante da escola, mas também diante do mundo social e, por outro lado, a minimizar as transformações da relação com o tempo, a linguagem e a experiência primeira do mundo (ou 'da vida', segundo termo recorrente nas falas dos jovens e que dá lugar a inúmeros comentários de Bernard Charlot), que exigem o trabalho de estudo e a apropriação da cultura escrita e da razão gráfica como instrumentos para pensar e aprender e não somente como meio de expressão e comunicação, trabalho de estudo e intenção de apropriação, um e outro constitutivos do projeto e da cultura escolares ${ }^{3}$, e para os quais os alunos parecem inegavelmente preparados pelos modos de socialização cognitiva e de linguagem realizada em sua família e em sua experiência social. Esse risco parece-me notavelmente aumentado pelo recurso a metodologias baseadas essencialmente em materiais de tipos 'declaratórios', analisados apenas pelo que dizem e não como modos de dizer ${ }^{4}$, e pela definição muito ampla da relação com o saber, acima mencionada, a qual temo seja muito pouco operacional para elaborar e conduzir um trabalho de pesquisa empírica ou que leve a lhe atribuir um objetivo grande demais.

\section{Uma noção que pede relações renovadas entre disciplinas de pesquisa em Educação}

Evidentemente, não é possível fazer uma separação entre o que os processos de produção das desigualdades sociais em matéria de acesso às técnicas intelectuais, aos saberes e ao êxito escolar devem à socialização e à experiência social 'não escolares' dos alunos, e o que devem ao funcionamento da instituição, às práticas e representações de seus agentes, pelo fato de a experiência escolar dos alunos construir-se sempre a partir de cada uma dessas esferas de atividades, de recursos e de obstáculos, de aberturas e de pressões. De fato, esses processos podem ser considerados resultantes do confronto entre, por um lado, as características e as disposições sociocognitivas dos alunos, suas relações com o(s) saber(es) e com o estudo, ligados a seus modos de socialização e de experiência 'não escolar', e que os preparam de modo muito desigual para fazer face aos requisitos das atividades e aprendizagens escolares e, por outro lado, a opacidade e o caráter implícito, invisível, desses requisitos, dos modos de funcionamento do sistema educacional e das práticas profissionais que nele são postas em ação. Problemática essa que está no cerne de nosso programa de pesquisas e que ultrapassa a da relação com o saber, se bem que a integre. Problemática que se liga a uma hipótese central de La reproduction ${ }^{5}$ e às reflexões e aos questionamentos iniciados por Bernstein (1975a), relativos tanto às relações próprias dos diferentes ambientes sociais entre modos de socialização, práticas de linguagem e orientações sociocognitivas, quanto ao caráter implícito ou explícito das formas de classificação, segmentação e transmissão do saber escolar (Bernstein 1975a) ou o caráter visível ou invisivel das pedagogias (1975b; 1992). Problemática que induz desde logo a estudar, no co-

\footnotetext{
3. A título heurístico e de maneira sem dúvida ainda muito genérica, designamos o conjunto dessas transformações como processo de 'secundarização' de sua experiência do mundo e de seus usos da linguagem, referindo-nos à distinção realizada por Bakhtine (1984) entre gêneros discursivos primários, espontâneos, e gêneros secundários. Pode-se ouvir um eco do que assim designamos nestas palavras de Oléron (1989), ao insistir sobre o fato de que a eficiência do raciocínio "não é possível a não ser que o sujeito não reaja imediatamente à situação ou ao problema proposto, mas efetue um rodeio pela reflexão, dúvida, mobilização ou elaboração de um plano, de um esquema, de uma representação da situação, de sua ação e de suas conseqüências".

4. As mesmas observações valeriam para muitas outras pesquisas além da de Charlot como, por exemplo, para grande parte das realizadas por François Dubet sobre 'experiência' dos atores (alunos, docentes...) da escola. 5. Bourdieu e Passeron ali escreveram, desde 1970, que se nosso sistema de ensino consagra e perpetua os privilégios culturais, "é porque a relação com a cultura que ele reconhece não está completamente dominada a não ser que a cultura que ele inculca tenha sido adquirida por familiarização [...]. Vê-se em primeiro lugar que, não oferecendo explicitamente o que ele exige, ele exige uniformemente de todos os que acolhe que possuam aquilo que não Ihes oferece".
} 
mum das classes, das escolas e dos estabelecimentos, as modalidades concretas das situações e das práticas de ensino e de aprendizagem, não só por elas mesmas, mas enquanto aí se importam, confrontam-se, põem à prova e podem transformar modos de interpretação, disposições e relações com o saber e com os saberes, com o estudo ou com o ensino, que não se reduzem ao aqui e agora dessas situações.

Apropriar-se de tal problemática tem várias conseqüências. Implica em dotar-se, para estudar essas modalidades concretas, de uma teoria da aprendizagem e dos saberes escolares e, a nosso ver, em considerar o fato de que esses saberes escolares (no sentido de saberes que exigem o tempo e o trabalho do estudo) requerem (e permitem) um trabalho de retomada, de descontextualização-recontextualização, de distanciamento, de redescrição dos saberes pragmáticos da experiência comum na qual a intenção de êxito é anterior à de compreensão (Piaget, 1974), trabalho de ‘secundarização' para o qual são essenciais a atividade e as ferramentas semióticas de representação. 0 que obriga desde logo desligar-se da forte reticência da Sociologia da Educação em levar em consideração a função e as atividades de transmissão e de apropriação do saber, e da postura que leva inúmeros sociólogos a considerar e a tratar essa função e essas atividades como se nada mais fossem do que ilusão, engano e mistificação, por trás das quais se ocultam as 'verdadeiras funções' (de reprodução social, de alienação, de domesticação...) da instituição escolar. E o que ao mesmo tempo requer desligar-se da assepsia social e, até mesmo, da ingenuidade e da cegueira sociológicas que pesam sobre parte importante da reflexão pedagógica, mas também das práticas e problemáticas de pesquisa em didática das disciplinas ou em psicologia da aprendizagem, ligadas a uma concepção do aluno ou do aprendiz como ser genérico, abstrato, universal, ou como puro sujeito cognitivo ou epistemológico, em detrimento do estudo das condutas dos sujeitos concretos atuando em situações sociais concretas e não depuradas para as necessidades do estudo. Nem substância ou característica ligada ao indiví- duo isolado ou a seu grupo social nem puro artefato construído pela instituição escolar isolada, a relação com o saber deve então ser pensada e estudada, numa abordagem relacional, como o produto de uma história e do confronto entre modos de socialização e universo de práticas de natureza necessariamente diferente. Uma das virtudes heurísticas da noção de relação com o saber, noção-encruzilhada como já se disse, poderia ser então a de nos induzir a superar o que parece ter-se estabelecido como uma espécie de divisão de trabalho entre sociologia da educação e sociologias da família ou da juventude, por exemplo, mas também, no seio da pesquisa em Educação, entre uma sociologia das desigualdades escolares, insuficientemente preocupada com as modalidades das atividades de transmissão dos saberes e das técnicas intelectuais, e uma pesquisa didática, pedagógica ou psicológica, insuficientemente preocupada com os diferentes contextos sociais e institucionais em que essas atividades sempre se situam. E de obrigar-nos, para iniciar essa superação, a estabelecer relações renovadas, tanto quanto à reflexão teórica e epistemológica quanto à concepção e à realização de pesquisas empiricas, entre Sociologia, Psicologia (no sentido amplo de disciplinas do psiquismo) e Didática, e a fazer com que essas diferentes disciplinas se interessem pela escola em sua especificidade, tanto quanto pelo que ela não é, para elaborar e levar a bom termo programas e trabalhos de pesquisa baseados numa abordagem racional, dialógica (Grossen, 1999), dos diferentes ambientes e das esferas de atividade e de experiência dos sujeitos sociais (Wallon, 1954; Baubion-Broye, 1998) e das diferentes categorias de obras (Meyerson, 1948, 1987) com que se defrontam.

\section{Uma noção que induz a um pensamento dialético das relações entre atividade e subjetividade}

No entanto, se a noção de relação com o saber apresenta-se assim fundamentalmente (talvez desmesuradamente?) anti-reducionista, 
como observam Colette Laterasse (2002), isso acontece porque ela nos induz a pensar as relações, no seio de cada esfera de experiência e de atividade dos sujeitos sociais, entre aquilo que, em École et savoir dans les banlieues... et ailleurs, havíamos chamado de componente epistemológica e componente identitária da relação com o saber, entre o que hoje prefiro designar como as gêneses instrumentais e as dinâmicas intersubjetivas (as quais incluem também a relação do sujeito consigo próprio) que presidem tanto a formação, em parte inconsciente, dos diferentes modos de relações com o(s) saber(es), quanto a apropriação ou a não-apropriação dos diversos saberes e das diversas técnicas intelectuais (no sentido mais amplo do termo) para cuja aprendizagem os sujeitos são convocados. Isso requer uma abordagem dialética e não unilateral das relações entre afeto e intelecto, em sucessão às concepções que foram as de Wallon ou de Vygotski (Rochex, 1999), mas também das de Piera Aulagnier que é, sem dúvida, no campo da Psicanálise, quem mais fez uso da noção de relação com o saber. Como Freud, ela insiste no fato de que a pulsão ou o desejo de saber são secundários, vindo em lugar do objeto que vem a se ocultar, e se revelam, pois 'busca de um saber sobre o desejo e, mais precisamente, sobre o desejo do outro', em 'resposta' ao enigma que tal desejo é e sempre será: "o que o desejo, diante da vacilação do objeto, coloca em seu lugar, é a questão da causa: ele assim se transmuta em desejo de saber" (Aulagnier, 1967). No entanto, essa primeira interrogação do desejo materno permanece solidária a uma intenção de domínio e de certeza, e a uma esperança de reprovação daquilo que, na realidade, vem contradizer a ilusão de onipotência e de completude, e Piera Aulagnier insiste também na necessidade de que a provação da castração obriga o sujeito a renunciar à onipotência e à completude e, conseqüentemente, a transformar sua relação com o saber.

Uma vez que saber e certeza coincidiram nos primeiros tempos da atividade psíquica e esta foi submetida à provação da castração, saber implica doravante a renúncia à certeza. E por essa renúncia ser simultaneamente o abandono da crença numa onisciência da mãe, suscetível de poder tornar-se a do sujeito, ela é renúncia a uma relação com o saber que exige que um outro particular possa sempre garantir ao sujeito a verdade do discurso. 0 saber escapa assim a uma economia do desejo em circuito fechado. Seu valor objetal é acrescido de um valor objetivo que o faz entrar em outro sistema de relações em que seu valor de verdade se prova em um universo de significações e de atividades partilhadas e garantidas, não mais por um outro e apenas sua palavra, mas pelos outros, seja por uma comunidade humana e seu patrimônio, intertexto que não tem nem origem nem fim. Afirma-se assim, não sem prejuízo, a supremacia da busca do saber sobre a exigência de certeza. 0 saber torna-se aquilo que permite ao sujeito aceitar o inaceitável da castração, por lhe oferecer um campo de ação inesgotável, no qual seu desejo pode desenvolver-se sem jamais obstinar-se sobre a finitude de seu objeto. Porém, esse campo é constituído de esferas de atividades específicas (linguagem, corporais, técnicas, conceituais, estéticas...) cujas normas e restrições, mas também os possíveis a que estas permitem ter acesso, provêm de gêneros e de gramáticas impessoais, e não dependem nem da subjetividade somente ou somente da boa vontade do sujeito nem das de outrem. E na possibilidade de se confrontar e de submeter-se a essas normas, gêneros e gramáticas impessoais, a esses instrumentos intelectuais e essas formas diferenciadas de ação que "não cabe a cada qual inventar para seu uso próprio", segundo a bela fórmula de Wallon (1942), é que o sujeito pode ser instituído e incessantemente solicitado para além de si mesmo, convocado ao mesmo tempo e solidariamente a desligar-se de si mesmo, de suas suficiências e insuficiências, de suas pertinências e de sua história passada, e a intercambiar com os outros.

0 campo social e seus diversos componentes, seus diferentes modos de atividade e as aprendizagens que requerem não são desde já somente um espaço em que se desenvolvem e 
onde reinam o desejo e a subjetividade; são um espaço em que estes podem reconfigurar-se, tomar um novo curso, à prova das normas irredutíveis às lógicas de dominação social ou de distinção - que regem as atividades partilhadas com outros, e dos possíveis que essas atividades e a configuração sociohistórica em que elas se inscrevem ${ }^{6}$, abrem potencialmente ao sujeito. Mais dialético a este respeito do que o de Lacan - porque, a meu ver, dá mais direito ao pensamento e à historicidade, por não ser ali o Eu somente essa instância condenada ao desconhecimento que é o Ego em Lacan -, o pensamento de Piera Aulagnier parece-me precioso naquilo que, em nome mesmo da psicanálise, ele se inscreve de fato de encontro a concepções 'subjetivistas' da psique e da subjetividade que, em nome da onipotência do sujeito ou da estrutura $^{7}$, acabam, de fato, por negar a estas toda historicidade, por não poderem comportar os contragolpes, sobre a subjetividade, da inscrição dos sujeitos em normas e atividades sociais independentes dessa subjetividade, por não poderem pensar de maneira realmente dialética as relações entre os registros e as gramáticas do impessoal e os processos de subjetivação ou de personalização.

\section{Uma concepção forte do sujeito não pode dispensar uma concepção forte do objeto}

Que haja muito a ganhar em enriquecer a noção de relação com o saber, tomando de empréstimo das aquisições e dos conceitos da psicanálise, é um ponto sobre o qual concordo sem reservas com os colegas do Cref, inclusive em sua crítica ao projeto de Bernard Charlot de fundar uma 'sociologia do sujeito' (cf. Charlot, 1997 e, quanto à crítica, Mosconi, 2000). Eu próprio (Rochex, 2000), paralelamente, discuti a pertinência de um projeto como esse nos seguintes termos:

Parece-me que o que provém da esfera de investigação e de análise da sociologia é menos o estudo do sujeito e de seu psiquismo do que o das evoluções sociohistóricas da forma-sujeito e das atividades e processos sociais que tornam possíveis essas evoluções e seu desenvolvimento desigual, segundo as formações e as categorias sociais. Minha tendência seria então pedir que a sociologia se dedicasse, muito mais do que faz hoje, ao estudo daquilo que Lucien Sève, há mais de vinte anos, designava, a título de um programa de pesquisa que depois não progrediu muito, como 'formas histórico-sociais de individualidade' (Sève, 1974), ao estabelecimento de uma espécie de cartografia ou topologia das provas e contradições sociais, dos eventos e fenômenos de transição (Baubion-Broye, 1998), das transformações das atividades e das temporalidades, nas quais os sujeitos são convocados e solicitados como instâncias de escolha, de arbitragem e de intersignificação, deixando inteiramente para as disciplinas do psiquismo (psicologia e psicanálise) o estudo daquilo que, no funcionamento e na história do psiquismo de cada um, está na origem das condutas que ele pode elaborar em resposta a essa convocação e a essa solicitação.

O debate, porém, tem talvez por objeto a natureza e o uso que uns e outros fazem desses empréstimos. Se a noção de relação com o saber remete ao que seria da ordem de uma disposição, de um modo de relação, relativamente estável, que o sujeito mantém com o saber, e que é o produto de uma história ao mesmo tempo pessoal e social, será que essa disposição e esse modo de relação poderão ser apreendidos no essencial sobre o registro do afeto, do prazer ou do sofrimento (Beillerot, 1989, p.166), e referidos preferencialmente aos começos da vida psíquica e às primeiras relações de objeto que ali se juntam, particularmente quando a indagação e a investigação dizem respeito a processos e sujeitos 'comuns', que não são afetados pelas patologias graves ligadas às 'deficiências' que podem sobrevir nessas primeiras relações de objeto? Indagação e in-

\footnotetext{
6. Cf. a este respeito Aulagnier, 1984.

7. Como acontece com a onipotência da estrutura do fantasma no 'velho' Lacan e em bom número de seus epígonos.
} 
vestigação não deveriam abrir espaço também à consideração de atividades, e não só de relações, de objeto, à sua especificidade, às suas normas e às da postura em que aí se convoca o sujeito, bem como aos possíveis contragolpes dessas atividades e da construção dessa postura, sobre o sujeito... e sobre suas relações de objeto? Em outras palavras, se se interessar pela relação com o saber é tentar encontrar elementos de resposta à pergunta ' $O$ que é que nos impele a saber? a aprender?'8, uma vez ultrapassadas aquelas primeiras etapas evocadas acima com Piera Aulagnier, o que nos impele a saber e/ou a aprender poderá ser pensado e estudado independentemente de tomar-se em consideração o que sabemos e já aprendemos, as modalidades segundo as quais o aprendemos e os poderes de ação e pensamento sobre o mundo e sobre nós mesmos que com isso conquistamos e podemos, a partir de então, exercer em outras circunstâncias? A componente cognitiva, epistemológica, instrumental, do processo de construção e de transformação da relação com o saber será secundária relativamente a sua componente subjetiva? Será ela essencialmente determinada por esta, em relações de dependência unilateral? Todos os nossos trabalhos me fazem pensar que esse não é o caso (tanto quanto o inverso) e que, a exemplo de Wallon e Vygotski, convém pensar as relações entre desenvolvimento cognitivo e desenvolvimento afetivo como não constantes, e como sendo, eles mesmos, objeto de um desenvolvimento no curso do qual não cessam de inverter-se os processos de dependência e de determinação. E temo que a preocupação, que eu próprio também tenho, de não dimensionar de maneira estreita o ato e os processos de aprendizagem, reduzindo-os a simples procedimentos ou mecanismos cognitivos, e de situá-los no âmago do processo de subjetivação (ou de personalização), não leve certos autores e certas conceptualizações a, ao revés, dimensionar de maneira estreita o trabalho cognitivo e as possibilidades para o sujeito de nele haurir e elaborar recursos subjetivos renovados. Não se poderá ler assim as fórmulas recorrentes em inúmeros discursos doxocológicos e vulgatas 'construtivistas', que reafirmam não haver aprendizagem sem um sujeito que aprende, mas que deixam de dizer que, por outro lado, também não há aprendizagem sem objeto, sem conteúdo, e que este pressiona de fora para dentro a atividade de aprendizagem que, portanto, não provém inteiramente do sujeito, caráter socialmente obrigado que é uma das condições de sua historicidade?

Não se poderá também ler desse modo a tentativa de Nicole Mosconi (2000) de "definir a maneira como a primeira relação com o saber, constituída no ambiente familiar, se transforma e se recompõe no ambiente escolar", considerando os quatro níveis que são os níveis estritamente psíquico ("que é o do fantasma", escreve ela, numa fórmula lapidar que não posso aprovar), intermediário (ou transicional, no sentido de Winnicott), institucional e social, sem jamais legitimar explicitamente o nível ou os registros cognitivo e epistemológico, ligados à natureza dos conteúdos da cultura escolar, o trabalho exigido pela apropriação desses conteúdos e as posturas a que são ali convocados esses sujeitos que são os alunos? Será que não se justifica vermos aí um risco importante de que, a uma concepção frágil demais do sujeito e de sua interioridade psíquica, corresponda uma concepção frágil demais do objeto (em particular dos conteúdos de saber) e de sua exterioridade cultural e institucional? Veria uma confirmação dessa hipótese na maneira pela qual Nicole Mosconi, nesse mesmo texto, pensa as relações entre instituição familiar, em que se constitui a personalidade psicofamiliar, e instituições educativas e escolares, etapas essenciais da socialização, por serem lugares privilegiados da constituição da personalidade psicossocial, e no modo como ela apresenta conseqüentemente as transformações da relação com o saber exigidas e construídas pela escolarização. "A escolarização", escreve ela, "vai impelir a criança a substituir seus

8. A distinção entre desejo de saber e desejo de aprender requer um trabalho aprofundado que, evidentemente, não tenho aqui espaço para empreender, mas a respeito do qual se poderá consultar Boimare, 1999. 
objetos privados de saber por objetos do saber comum que valem, na sociedade, por sua instituição social e, em primeiríssimo lugar, pela instituição escolar", e essa transformação da relação com o saber será ligada à constituição da personalidade psicossocial, que ultrapassa pois a personalidade psicofamiliar e que a experiência do trabalho e da formação profissional obrigará mais tarde a novas reelaborações.

Porém, além do risco de que tais formulações possam fazer crer que o espaço familiar e a personalidade psicofamiliar teriam a ver essencialmente com saberes de ordem privada, o que evidentemente não é o caso, uma vez que ali se constroem aquisições, eminentemente comuns, entre as primeiras das quais sem dúvida figuram a aquisição da linguagem e a de inúmeras primeiras técnicas intelectuais e/ou corporais, parece-me que seria dimensionar de maneira estreita as transformações da relação com o saber que, ao mesmo tempo, requer e permite a escolarização. A especificidade desta, segundo penso, não reside inicialmente na passagem de objetos de saber de ordem privada a objetos de saber comuns, pois estes últimos existem felizmente bem antes da escolarização e continuam a se desenvolver em grande parte fora desta, mas na necessidade, para o aluno, de construir uma relação secundária, no sentido do processo de secundarização anteriormente mencionado, com seus saberes e sua experiência comuns do mundo, da linguagem e de si mesmo, relação secundária esta adequada ao tempo e ao trabalho do estudo. Assim, a iniciação na escrita, a qual antropologicamente começou ligada à escola, requer e permite transformar sua relação com a linguagem em uma relação reflexiva, na qual a linguagem, de ferramenta de ação que pode esquecer de si mesma em sua eficácia, torna-se progressivamente objeto de pensamento cujas regras e modos de funcionamento são então passíveis de serem descritos e objetivados (Goody, 1977; 1993; Olson, 1994; Lahire, 1993a). A escola (no sentido da skholé grega) é a partir de então a instituição e o lugar por excelência onde se visa a que possam ser transmitidos e apropriados, não quaisquer sabe- res e práticas, mas prioritariamente determinados saberes e determinadas práticas que, ao mesmo tempo, requerem e permitem um trabalho e uma postura de objetivação, de distanciamento do mundo (pelo menos de certos objetos do mundo), da linguagem e da experiência que temos com ela, trabalho e postura que fazem deles objeto de estranheza ou de inquietude, de questionamento, de reflexão, de análise e de saber e que, no mesmo movimento, constituem o sujeito como foco de suas atividades. Será que não levar em consideração ou minimizar essa especificidade da escola e do processo de escolarização não levará, a partir de preocupações e de quadros teóricos diferentes, a adotar, ainda que sem o saber, a postura de desespecificação, até mesmo de desescolarização do universo e da experiência escolares, que anteriormente criticamos em certos trabalhos e certas pesquisas de Sociologia da Educação, postura a meu ver danosa a uma melhor compreensão dos modos de construção, de comprovação, de reelaboração das diferentes relações com o saber e com os saberes, que resultam da pluralidade e da confrontação das diferentes instituições e dos diferentes ambientes na encruzilhada dos quais os sujeitos se interpretam, se reinterpretam e não param de se produzir?

Se a noção de relação com o saber é uma noção-encruzilhada entre diferentes disciplinas de pesquisa, se ela induz a um pensamento relacional do que se joga para os sujeitos em termos de saber(es) e de aprendizagem no confronto entre ambientes e esferas de experiência de natureza diferente e regidos por normas específicas, ela não conservará esse valor heurístico a não ser que tome em consideração a especificidade dos diferentes universos de saberes e de práticas, e de saber conjugar a uma concepção forte de sujeito, irredutível a uma máquina cognitiva ou a uma abordagem solipsista, uma concepção igualmente forte do objeto, ou seja, dos diferentes tipos de objetos e de práticas de saber, e da pluralidade das instituições que constituem nosso mundo social e fazem viver suas contradições. Vale dizer que isso não poderia acontecer senão colocando no 
cerne de nossos trabalhos e de nossas elaborações teóricas, não só as convergências que essa noção implica, mas também os debates sem os quais essas convergências logo se revelariam insuficientes para alimentar o trabalho de nossas comunidades de pesquisa. Com este artigo, meu empenho foi contribuir para o esclarecimento de parte desses debates.

\section{Referências bibliográficas}

AULAGNIER, P. Le désir de savoir dans ses rapports à la transgression. L'inconscient, v. 1, 1967. (Reproduzido em P. Aulagnier. Un interprète en quête de sens. Paris: Ramsay, 1986).

Elle une 'zone sinistrée'. Adolescence, v. 1. 1984.

BAKHTINE, M. Estéthique de la création verbale. Paris: Gallimard, 1984.

BARTHEZ, J.-C. De I'habitus expliquant à l'habitus expliqué. Sociologie du Sud-Est, v. 26, p. 17-49. 1980.

BAUBION, B. A. (Dir.). Événements de vie, transitions et construction de la personne. Toulouse: Éd. Érès, 1998.

BAUTIER, É.; ROCHEX, J.-Y. L'expérience scolaire des 'nouveaux lycéens': démocratisation ou massification? Paris: Armand Colin, 1998.

BAUTIER, É. Aspects sociocognitifs du langage: quelques hypothèses. Langage et Société, v. 47, p. 55-84. 1989.

Pratiques langagières, pratiques sociales. Paris: L'Harmattan, 1995.

BEILLEROT, J. Le rapport au savoir: une notion en formation. In: BEILLEROT, J. et al. (Orgs.). Savoir et rapport au savoir: élaborations théoriques et cliniques. Paris: L'Harmattan, 1989.

Note sur le modus operandi du rapport au savoir. In: BEILLEROT, J., BLANCHARD-LAVILLE, C., MOSCONI, N. (Orgs.). Pour une clinique du rapport au savoir. Paris: L'Harmattan, 1996.

BERNSTEIN, B. Langage et classes sociales. Paris: Éd. De Minuit, 1975a.

Classes et pédagogies: visibles et invisibles. Paris: CERI-OCDE, 1975b.

La construction du discours pédagogique et les modalités de sa pratique. Critiques Sociales, v. 3-4, p. 20-58. 1992.

BOIMARE, S. La peur d'apprendre. Paris: Dunod, 1999.

CHABCHOUB, A. (Dir.). Rapports aux savoirs et apprentissage des sciences. Faculté des Sciences de Sfax. Association tunisienne de recherches didactiques. 2000.

CHARLOT, B. Du rapport au savoir: éléments pour une théorie. Paris: Anthropos, 1997.

Le rapport au savoir en milieu populaire: une recherche dans les lycées professionels de banlieue. Paris: Anthropos, 1999.

CHARLOT, B.; BAUTIER, É.; ROCHEX, J.-Y. École e savoir dans les banlieues... et ailleurs. Paris: Armand Colin, 1992.

CHARLOT, B., ROCHEX, J.-Y. L'enfant-élève: dynamiques familiales et expérience scolaire. Lien Social et Politiques, v. 35, p. 137151. 1996.

FORQUIN, J.-C. Le débat sur l'école et la culture chez les théoriciens et sociologues de l'éducation en Grande-Bretagne. Tese (Doutorado na área de Estado) - Universidade Louis-Pasteur, Estrasburgo. 1987.

École et culture: le point de vue des sociologues britanniques. Bruxelas: De Boeck, 1989.

GIBSON, R. Structuralism and education. Londres: Hodden and Stoughton, 1984. 
GOODY, J. La raison graphique. Paris: Éd. De Minuit, 1979.

Entre l'oralité et l'écriture. Paris: PUF, 1994.

GROSSEN, M. Approche dialogique des processus de transmission-acquisition de savoirs: une brève introduction. Actualités psychologiques, v. 7. Institut de Psychologie, Université de Lausanne, p. 1-32. 1999.

HÉRAN, F. La seconde nature de l'habitus: tradition philosophique et sens commun dans le langage sociologique. Revue Française de Sociologie, v. XXVIII, p. 385-416. 1987.

LAHIRE, B. Culture écrite et inégalités scolaires. Lyon: Presses Universitaires de Lyon, 1993a.

La raison des plus faibles. Lille: Presses Universitaires de Lille, 1993b.

Tableaux de familles: heurs et malheurs scolaires en milieux populaires. Paris: Gallimar-Seuil, 1996.

L'homme pluriel. Paris: Nathan, 1998.

LATERRASSE, C. Du rapport au savoir à l'école et à l'université. Paris: L'Harmattan, 2000.

LAURENS, J.-P. Un sur 500: la réussite scolaire en milieu populaire. Toulouse: Presses Universitaires du Mirail, 1992.

MEYERSON, I. Les fonctions psychologiques et les oeuvres. Paris: Reed. Albin Michel, 1995.

Écrits 1920-1983: pour une psychologie historique. Paris: PUF, 1987.

MOSCONI, N. Pour une clinique du rapport au savoir à fondation anthropologique. In: MOSCONI, N.; BELLLEROT, J.; BLANCHARD-

LAVILLE, C. (Orgs.). Formes et formations du rapport au savoir. Paris: L'Harmattan, 2000.

OLÉRON, P. Le raisonnement. Paris: PUF, 1989.

OLSON, D. L'univers de l'écrit. Paris: Retz, 1998.

PIAGET, J. Réussir et comprendre. Paris: PUF, 1974.

ROCHEX, J.-Y. Le sens de l'expérience scolaire. Paris: PUF, 1995.

. Lev Vygotski et Henri Wallon: une pensée dialectique des rapports entre pensée et affect. In: CLOT, Y. (Org.). Avec Vygotski. Paris: Éd. La Dispute, 1999.

Expérience scolaire et procès de subjectivation: I'élève et ses milieux, note de synthèse pour l'habilitation à diriger des recherches. Paris: Université Paris VIII, 2000.

Échec scolaire et démocratisation: enjeux, réalités, concepts, problématiques et résultats de recherche. Revue Suisse des Sciences de l'Éducation, v. 23, n. 2, p. 339-356. 2001.

SÈVE, L. Marxisme et théorie de la personnalité. 30 ed. Paris: Éditions Sociales, 1974.

TERRAIL, J.-P. Destins ouvriers. La fin d'une classe? Paris: PUF, 1990.

WALLON, H. De l'acte à la pensée. Paris: Flammarion, 1942.

. Les milieux, les gropes et la psychogenèse de I=enfant. Cahiers Internationaux de Sociologie. 1954. Reproduzido em Enfance, número especial 'Henri Wallon. Psychologie et Éducation de l'Enfance', 1985, p. 95-104.

ZÉROULOU, Z. Mobilisations familiales et conditions de scolarisation des enfants: le cas de l'immigration algérienne. Tese (Doutorado em Sociologia)- Université Lille-l. 1985. 